\title{
How Can Bill and Melinda Gates Increase Other People's Donations to Fund Public Goods?
}

\section{Dean Karlan and John A. List}

\begin{abstract}
We develop a simple theory which formally describes how charities can resolve the information asymmetry problems faced by small donors by working with large donors to generate quality signals. To test the model, we conducted two large-scale natural field experiments. In the first experiment, a charity focusing on poverty reduction solicited donations from prior donors and either announced a matching grant from the Bill and Melinda Gates Foundation, or made no mention of a match. In the second field experiment, the same charity sent direct mail solicitations to individuals who had not previously donated to the charity, and tested whether naming the Bill and Melinda Gates Foundation as the matching donor was more effective than not identifying the name of the matching donor. The first experiment demonstrates that the matching grant condition generates more and larger donations relative to no match. The second experiment shows that providing a credible quality signal by identifying the matching donor generates even more and larger donations than not naming the matching donor. Importantly, the treatment effects persist long after the matching period, and the quality signal is quite heterogeneous - the Gates' effect is much larger for prospective donors who had a record of giving to "poverty-oriented" charities. These two pieces of evidence support our model of quality signals as a key mechanism through which matching gifts inspire donors to give.
\end{abstract}

JEL Codes: D12, D71, D82, H41, O12

Keywords: public goods; charitable fundraising; asymmetric information; matching grant. 


\title{
How Can Bill and Melinda Gates Increase Other People's Donations to Fund Public Goods?
}

\author{
Dean Karlan \\ Yale University and MIT Jameel Poverty Action Lab \\ John A. List \\ University of Chicago
}

Contact info: Dean Karlan: dean.karlan@yale.edu; Yale University, Innovations for Poverty Action, Jameel Poverty Action Lab and NBER; John A. List: jlist@uchicago.edu; University of Chicago and NBER. The authors thank TechnoServe for collaborating on this field experiment, and the Bill and Melinda Gates Foundation for providing the matching grant to TechnoServe. All opinions reported here are those of the authors. Karlan thanks the Alfred B. Sloan Foundation and the National Science Foundation for support. The authors thank Selvan Kumar, Rachel Strohm and James Tan for research assistance.

CGD is grateful to its funders and board of directors for support of this work.

Dean Karlan and John A. List . 2012. "How Can Bill and Melinda Gates Increase Other People’s Donations to Fund Public Goods?.” CGD Working Paper 292. Washington, D.C.: Center for Global Development.

http://www.cgdev.org/content/publications/detail/1426125

Center for Global Development 1800 Massachusetts Ave., NW Washington, DC 20036

202.416.4000

(f) 202.416 .4050

www.cgdev.org
The Center for Global Development is an independent, nonprofit policy research organization dedicated to reducing global poverty and inequality and to making globalization work for the poor. Use and dissemination of this Working Paper is encouraged; however, reproduced copies may not be used for commercial purposes. Further usage is permitted under the terms of the Creative Commons License.

The views expressed in CGD Working Papers are those of the authors and should not be attributed to the board of directors or funders of the Center for Global Development. 


\section{Introduction}

The combination of shrinking public budgets and devolutionary trends in government has policymakers around the globe struggling to finance public goods. Private charities, which have grown significantly in the past several decades, can substitute for the government in the provision of public goods. Since 1970, charitable gifts in the United States have grown seventeen-fold, nearly doubling the rate of growth in the S\&P 500 over the same period; overall US giving to charitable and religious causes now exceeds $2 \%$ of Gross Domestic Product in the United States (List, 2011).

Even if dollars can be attracted, skeptics, particularly in the space of aid to developing countries, question whether aid can work to alleviate poverty (Easterly, 2006). The high price of information might cause a failure in the market for charitable services. Individuals, keen to act on their altruism, may not do so because they lack information about aid effectiveness. Large donors, who may be better equipped to assess the quality of organizations, often announce their gifts publicly. While this public giving may be attributable to vanity (see, e.g., Karlan and McConnell, 2012), quality signaling and expectation of social mimicry are also oft named mechanisms.

The early seminal models of giving did not consider lead donors and sequential charitable gifts (Andreoni, 1989, 1990), but instead developed a theory of giving that focused on the private consumption utility of giving - the "warm glow" - alongside other motives such as altruism. However, an increasing amount of evidence from the field suggests an important role for leadership giving in encouraging others to give. For example, List and LuckingReiley (2002) find that announcing higher levels of seed money increases giving, but that the offer of a rebate contingent on achievement of a fundraising goal has no discernible impact on giving. Similarly, Karlan and List (2007) find that announcing a matching grant increases giving for a liberal, politically-oriented charity, but that this increase is unaffected by changes in the matching ratio. The underlying mechanism at work in such studies remains illunderstood, however. ${ }^{1}$

The theoretical literature has also yet to coalesce around the underlying motivation for why leadership gifts work. Hermalin (1998) explores the role of leadership within a firm, and shows that under symmetric information about the marginal product of effort, there is a stable equilibrium where everyone in the organization free rides to a certain extent.

\footnotetext{
${ }^{1}$ Other work suggests that upfront money may not signal charity quality. For example, Meier (2007) finds that in a fundraising campaign for two social funds at a university, students respond positively to a matching grant in the short run, but reduce their post-matching period contribution. Thus, there was no net difference in funds raised in the long term.
} 
However, if there is asymmetric information, then the leader can convince the followers to exert full effort by exerting full effort himself —-leading by example — which serves as a signal to workers that effort has a higher marginal product. Applied to public goods, Hermalin's findings suggest a role for leadership giving, independent of warm-glow utility, based on the asymmetry of information about the returns to different charitable organizations.

More closely linked to our work, Vesterlund (2003) develops a novel theory that seeks to explain sequential fundraising. Similar to Hermalin, Vesterlund assumes that donors possess imperfect information about charity quality, and shows that if some donors can acquire sufficient information to reveal quality, then announcements about prior donor giving levels can induce additional giving through information revelation. Andreoni (2006) adds richly to the model by including two important variations: the public good can take on more than two quality levels, and the leader can be treated as endogenous rather than exogenous. The first admits an extra dilemma, since only extraordinarily large gifts by the leader can signal that the charity is of high quality. The second creates an informational public good, where the equilibrium calls for only the richest single person to be the leader. Andreoni's extensions cogently explain how charities can serve as important middle-men in transforming donor preferences into immediate actions.

To examine how and why leadership giving affects prospective donors, we begin by presenting a simple theoretical model that outlines the underlying mechanism by which leadership gifts may effect the behavior of marginal givers. Under the quality signaling theory of leadership gifts, the leader's information should have important heterogeneous effects across agents: for those leaders who are credible, the sign of the signaling effect is positive. Alternatively, if the leader lacks credibility, the leadership signal should be unimportant, and not affect giving rates.

To test the predictions from our model, we teamed with TechnoServe, a medium sized ( $\$ 42.2 \mathrm{~m} 2008$ revenue) charity focused on international development and poverty reduction. We conducted two natural field experiments through their normal direct mail fundraising efforts. In our first field experiment, we examine the impact of a matching grant provided by the Bill and Melinda Gates Foundation (BMGF) at a ratio of \$2:\$1 versus a control group that received no match offer. The sample frame for this experiment consisted entirely of prior donors to TechnoServe.

In our second field experiment, we examine the impact of naming the matching donor, the BMGF, versus not providing the identity of the matching donor. In this case, the sample consists entirely of individuals who had not previously donated to TechnoServe. Importantly, in this second field experiment, we also obtained information about the type of charities the potential donor had supported in the past. This non-experimental variation in donor preferences allows us to test for heterogeneous treatment effects. In both experiments we are able to track long-term giving after the window for matched giving concludes, which is important for teasing apart the mechanism through which the matching grant affects donation levels. 
In the first experiment, we find in our match period that simply offering a $\$ 2: \$ 1$ matching grant significantly increased average revenue per solicitation by $81 \%$, or 12.3 cents, from prior donors. Importantly, on the extensive margin the match offer increased the probability of an individual donating by $79 \%$. In the second experiment, we find that the quality signal of naming BMGF as the source of matching funds significantly increased average revenue per solicitation by $51 \%$, or 11.8 cents, amongst non-prior donors, and increased the probability of an individual donating by $26 \%$. The quality signal increased the probability of a non-prior donor giving, but did not significantly increase average gift size conditional on giving.

We also find heterogeneous effects of the quality signal: the impact on respondents who were past donors to poverty-oriented charities is roughly 3.75 times larger than on donors to other types of charities. We posit that those who have given to worldwide poverty issues previously are more likely to identify the BMGF as a large foundation dedicated to poverty alleviation (as opposed to identifying BMGF as a Microsoft corporate foundation, or lacking familiarity with it entirely). With this knowledge about BMGF's activities, individuals are more likely to perceive the matching donation as a signal about the quality of TechnoServe, as BMGF is capable of incurring significant costs to identify worthy causes. Thus, our interpretation is that the matching donation from the BMGF has a larger average impact on the response rate and amount given because the information signaled by the BMGF gift allows donors to overcome the market failure associated with asymmetric information, and to act on their altruism.

Importantly, in both experiments we also observe donations to TechnoServe after our experimental match period has ended. This allows us to differentiate between various factors affecting giving. For example, our theory suggests that there could be two motivations to give because of the BMGF endorsement. One is the signal about the charity's quality; the second is the desire to emulate one of the richest people in the world. This vainglorious motivation would work through the same mechanisms that caused donors to give more when attractive women solicited a donation (Landry et al., 2006). If the BMGF endorsement enters potential donors' utility functions through this superficial, non-quality signal mechanism, and such a mechanism is only short-lived, then we should only observe a shortterm change in giving. What we observe, however, is that people informed about the BMGF quality signal continue to give at higher rates well after the matching period, lending support to the quality signaling interpretation.

Our results have important implications for the design of fundraising campaigns, and add to a growing body of empirical literature analyzing the psychology and economics of charitable giving. In addition, the results suggest that maybe governments can mitigate inefficiently low levels of charitable giving for international development by acting in the role of the lead giver. This insight could also be applied to resolving other market failures, such as suboptimal consumption of environmental goods or new technologies, by encouraging governments or other large donors to send quality signals through leadership giving. 
The remainder of this study proceeds as follows. In Section II we describe our theoretical framework, Section III summarizes the experimental design and results, and Section IV concludes.

\section{Theoretical Framework}

To provide a theoretical framework for interpretation of our empirical results, we present a simple theory following Andreoni $(1989,1990)$ and Landry et al. $(2006,2010)$. An agent $i \in \Omega$ has utility that is additively separable into utility $u_{i}$ from consuming a numeraire good, $y_{i}$, expected utility $h_{i}(\bullet)$ from a public $\operatorname{good}(G)$, and a composite utility term, $f_{i}(\bullet)$, which is conceived of as a warm glow component. In choosing a donation level, $b_{i}$, agent $i$ derives utility according to:

$$
V_{i}=u_{i}\left(y_{i}\left(b_{i}\right)\right)+h_{i}(G)+f_{i}\left(b_{i}\right)
$$

where numeraire consumption is determined by the budget of the agent, $y_{i}=w_{i}-b_{i}$. Total public good provision is given by $G=\sum b_{i}$. We assume that $f_{i}$ is concave and that $u_{i}$ and $b_{i}$ are (strictly) increasing and concave.

This simple set-up elucidates several facts. First, basic predictions of price changes-e.g., lowering the price of charitable giving through tax changes or matching grants, the common intuition is that people should increase demand for contributions; therefore, the donation level $b_{i}$ increases, as does $\mathrm{G}$.

Three decades of empirical work have been devoted to estimating the price elasticity of charitable contributions, though most of them have examined price changes induced thorough rebate mechanisms and tax codes (see the work of Feldstein, 1975, Clotfelter, 1985, Randolph, 1995, Auten et al., 2002, Peloza and Steel, 2005). Important experimental work has also shown the power of framing, and that price changes via matching grants might impact giving more than those operating through rebate mechanisms (Eckel and Grossman, 2003).

Beyond these price effects, however, we also expect matched gifts to influence expected utility $h_{i}$ from the public good provided by charities. As discussed in Vesterlund (2003) and Andreoni (2006), donors may be incompletely informed about the true value of the public good. A charity can thus gain credibility and increase the expected marginal utility to an agent by using mechanisms that provide credible signals of charitable quality. One such effect might come via the announcement of matching funds. Alternatively, it is possible that potential donors might perceive the matching grant as a 'marketing trick,' in which case, one would expect the match to have either no effect or a slightly negative effect on donations. Even if matching grants are perceived as credible, they might actually reduce donations by decreasing the marginal utility of the public good being bought. For this to happen, the 
reduction in marginal utility needs to outweigh the price effect resulting from the match, which depends on many factors, including the match ratio and beliefs about others' giving.

Importantly, however, one aspect of this model that has not been explored empirically is the channel through which the match might operate. In many fund-raising campaigns, charities place importance on both participation rates and aggregate contribution levels. As such, it is important for the charity to influence the marginal utility of giving, i.e. the derivative of (1) with respect to $b_{i}$. The simple framework above provides two distinct channels through which the fundraiser can influence donation decisions.

First, the expected utility from the public good, $b_{i}$, can be influenced by announcing that a lead donor has come forward and is supporting the cause. Such an announcement can alter the perceived credibility of the charity, in both the short run and the long run, for prospective donors who view the announcement as credible and informative. Second, the composite utility term $f_{i}$ may depend on factors such as warm glow, or the fact that the donor wants to emulate the lead donor. Consonant with this notion, Landry et al. (2010) report that solicitor characteristics, such as female physical attractiveness, influence giving in the short run but have no influence on long-run donations. In this way, influences on the composite utility term tend to be short-lived (see also Della Vigna et al., 2011). Viewed through the lens of the model, therefore, it is possible to explore the effect of lead donor gifts by examining their effects on prospective donors in both the short and long runs, and among donors who are better and worse informed about the quality signal.

\section{Insiders versus Outsiders}

To operationalize the idea that lead donor gifts might have heterogeneous effects, we partition the set $\Omega$ of agents into two types: (i) individuals who have never given to a charity in sector i, and therefore have less information about such types $\left(\Omega^{\mathrm{NG}}\right.$, never given) and (ii) previous givers to charity types in sector i $\left(\Omega^{\mathrm{G}}\right.$, given):

$$
\Omega=\Omega^{\mathrm{NG}} \text { union } \Omega^{\mathrm{G}}
$$

Importantly, givers to charity sector $i$ reveal either a high marginal valuation for the public good provided by such charity types, a higher realization of the composite utility term (i.e., a large warm glow or a distaste for not giving), or some combination thereof. Ceteris paribus, we would thus expect that such households are more likely to contribute and to provide larger donations than a non-previously-giving household when a charity from sector $i$ approaches them. Furthermore, $\Omega^{\mathrm{G}}$ household donations should be more influenced by a credible lead donor who has an established reputation in sector $i$ compared to $\Omega^{\mathrm{NG}}$ households. This is because such lead donors influence the expected utility $h_{i}$ from the public good for $\Omega^{\mathrm{G}}$ households more so than for $\Omega^{\mathrm{NG}}$ households. 
We thus identify two channels in which a gift from a lead donor can operate. First, the lead donor can alter the expected value of the public good via the signal of charitable quality. Second, and in contrast, the lead donor's gift can operate solely via the instantaneous realization of the composite utility term $f_{i}$ smaller donors might simply donate in the presence of a matching gift because they wish to be like the lead donor. Nike captured this sentiment well in a famous shoe commercial: you, too, can Be Like Mike.

\section{Short Run vs. Long Run}

Theory also guides our thinking on short run vs. long run effects: if the lead donor's gift provides a durable signal of charitable quality, then giving levels should increase after the announcement of the leader's donation both in the short and the long run. Alternatively, if the lead donor affect is operating purely through the composite utility term, $f_{i}$, the effect of the lead donor will be short lived.

As a thought experiment, consider the marginal donor who contributes to a campaign with matched donations because of his composite utility term. If such an agent is approached in a follow-up campaign without the match offer, the realization of the composite utility term would be lower. Ceteris paribus, we would therefore expect a weakly lower contribution from such an agent. Alternatively, if this marginal donor was attracted via the match because of the quality signal, future contributions might remain high if the quality signal is durable. We collect data both within the period when donations are matched (the short run) as well as after the matching period expires (the long run) in order to test this theory.

\section{Experimental Motivation, Setting, and Design}

The 501(c) 3 organization TechnoServe aims to raise the incomes of entrepreneurial men and women in impoverished countries by helping them to build up their businesses and farms. They serve Asia, Africa, Central America, and South America, and rely on individual contributions as well as large grants to finance their mission. BMGF is a major donor of TechnoServe, and provided the necessary matching funds for this set of field experiments.

\section{Experiment \# 1: Matching Grant versus Non-Matching Grant, Sample Frame of Prior Donors}

To establish the positive effect of a matching grant in this context, our first experiment estimates the elasticity for donations with a matching grant compared to those without a match. As discussed above, several theories suggest that a matching grant may not generate higher giving. To wit, individuals may believe the lead donor will donate the money regardless, perceive the charity as more satiated (i.e. the marginal product for the public good is reduced), or simply shift donations inter-temporally but not increase total giving. Furthermore, the empirical evidence is mixed. Karlan and List (2007) find that matching grants increase giving to a liberal politically-oriented charity, but only in states which voted 
more liberally in presidential elections. Meier (2006) finds matching grants increase giving in the short run but not the long run. Finally, Karlan, List, and Shafir (2011) find that matching grants work positively for recent supporters but negatively for prior-but-not-recent supporters. This mixed evidence makes imperative the need for refinement of theoretical understanding of the conditions under which matching grants change the donation patterns of heterogeneous groups of donors.

Our sample frame for this first natural field experiment consists of 52,988 prior donors to TechnoServe. Solicitation letters were mailed in December 2009, and responses were tracked until March 2010, at which point no further donations were received from this round of solicitation. Donors were randomly assigned to receive letters with or without information about the BMGF's matching grant. The randomization process and distribution of the letters were carried out by the direct marketing firm hired by TechnoServe.

\section{Experiment \# 2: Named Matching Grant vs. Unnamed Matching Grant, Sample Frame of Prospective Donors}

Lesser-known charities often experience difficulty in raising funds. This is commonly attributed to a lack of public awareness about the nature and quality of the work that they perform. If potential donors have preferences over organizational quality, one means for lesser-known organizations to increase donations is to use quality signals to demonstrate their own credibility.

Our model shows that quality signals can operate through information: when potential donors have information about leadership donors' gifts to an organization, it may act as a signal of the charity's quality. However, the information content of the message critically relies on the leadership donor. In this second natural field experiment, we use a campaign in which half of our sample of potential donors were offered a 2:1 matching grant from a named and prestigious donor (the BMGF), and the other half were offered a 2:1 matching grant from an unnamed donor. As with the first experiment, the randomization process and distribution of the letters were carried out by the direct marketing firm hired by TechnoServe.

Our theory suggests that identification of the lead donor might be important for solicitees. As the largest private foundation in the world, BMGF might increase donations via two potential channels. First, it could potentially affect the expected utility from the public good, $h_{i}$; this is because the expected quality is enhanced through the lead donor's announcement of support for the lesser-known organization. Second, the composite utility term $f_{i}$ may depend on factors such as warm glow, or the fact that the solicitee wants to emulate the lead donor. Both of these factors should serve to increase giving during the matching period.

Our sample frame for this natural field experiment consists of a distinct pool of 61,483 prospective donors who had previously given to charities other than TechnoServe, but had 
not given to TechnoServe itself. Since TechnoServe purchased the list of potential donors from other charities, we can identify the charity of origin for all donors in our sample. ${ }^{2}$ We use this information to examine heterogeneity among the potential donors, assessing whether the quality signal provided by BMGF is more effective with those who have more information about poverty-oriented charities than with those who have less. We also note that our classification as "poverty-oriented" coincides perfectly with whether the charity had received prior support from the BMGF. It is important to note that while we could not induce exogenous variation in the subjects' pre-treatment donation set, our main identification assumption is that those who have given to poverty-oriented charities in the past will be marginally better informed about the quality of a poverty-oriented charity and the role of BMGF in this space. Preferences may also vary between these two groups of donors, but baseline comparisons allow us to infer their importance.

\section{Experimental Results}

Table 1 presents the results for experiment 1, including summaries of giving both during and after the match period. Table 2 presents the same for experiment 2 , and includes tests for heterogeneity based on the source of the prospective donor's name.

Because we are analyzing data from a randomized experiment, our empirical strategy is straightforward. For both experiments, we use OLS to estimate the following specification:

$$
\mathrm{Y}=\mathrm{a}_{0}+\mathrm{a}_{1} \mathrm{~T}_{1}+\mathrm{e}
$$

where $\mathrm{Y}$ is the dependent variable and $\mathrm{T}_{1}$ is a dichotomous variable indicating whether the respondent was exposed to the treatment. Using donation amount as the dependent variable estimates treatment effects on average revenue per solicitation. Using a binary indicator of whether the solicitee gave in any amount as the dependent variable estimates how the treatment affected the average probability of an individual giving. In order to estimate the impact of the treatment on average gift size, we restrict the sample to those who gave and use gift amount as the dependent variable; this last approach deviates from the experimental design since selection into giving may be heterogeneous with respect to wealth, or many other unobserved factors.

Our first result from experiment 1, presented in Table 1 Panel A, is that the announcement of a matching grant from BMGF was effective at increasing donations from prior donors during the matching period. We find that average revenue per solicitation was $\$ 0.13$ higher

\footnotetext{
2 We identify charities as "poverty-oriented" if they have received prior support from BMGF. The charities are Accion (poverty-oriented, prior support from BMGF), American Indian College Fund (non-poverty, no prior support from BMGF), Drug Policy Alliance (non-poverty, no prior support from BMGF), Freedom from Hunger (poverty-oriented, prior support from BMGF), TAG: Tony and Alicia Gwynn Foundation (non-poverty, no prior support from BMGF), USA for UNHCR (non-poverty, no prior support from BMGF) and Women for Women (non-poverty, no prior support from BMGF). Information on support from BMGF determined by accessing the publically available 990 tax records of each of the non-profit organizations.
} 
among respondents who received the treatment mailer $(\$ 0.28)$ than among those who received the control (\$0.15), an increase of $81 \%$. Our empirical results indicate that the match increased the likelihood of an individual giving by 0.4 percentage points, an increase of $80 \%$ from $0.5 \%$ to $0.9 \%$. Interestingly, the match did not increase gift size among those who gave ( $\$ 30.75$ in treatment compared to $\$ 30.48$ in control) - its effect was simply to increase the probability of giving.

Similar results were also seen after the officially announced end-date of the matching treatment. Panel B shows that those who received the treatment were more likely to give again, as the likelihood of a repeat gift increases from $0.24 \%$ among the control group to $0.46 \%$ among the treated ( $\mathrm{p}$-value of difference $=0.000$ ), and average future gift unconditional on giving increases from $\$ 0.112$ to $\$ 0.343$ ( $\mathrm{p}$-value of difference $=0.057$ ). This reinforces the idea that the matched grant does not affect individual giving through the price mechanism, nor by inspiring a desire to emulate the Bill and Melinda Gates Foundation, but rather through a quality signal that retains its value after the initial direct marketing solicitation and generates a more loyal donor.

Results from experiment 2, shown in Table 2, reveals that solicitations which named BMGF as the matching donor were much more effective than solicitations that did not name the matching donor, increasing average revenue per solicitation by $\$ 0.12$, from $\$ 0.29$ to $\$ 0.41$, or $40 \%$ ( $\mathrm{p}$-value of difference $=0.003)$. The naming treatment also increased the probability of an individual giving: on the extensive margin the naming gift increased giving rates by 0.23 percentage points (from $0.9 \%$ to $1.1 \%$, p-value of difference $=0.004$ ).

As was observed in experiment 1 , the treatment effect did not dissipate after the matching deadline. This result provides further credence to the hypothesis that leadership gifts increase individual giving due to the durable quality signal they provide: the repeat giving rate increases from $0.4 \%$ to $0.6 \%$ (p-value of difference $=0.001)$, and average gift unconditional on giving increases from $\$ 0.118$ to $\$ 0.188$ ( $\mathrm{p}$-value of difference $=0.058$ ).

Given the unique nature of our data, we can dig deeper into this result by focusing more closely on the types of donors who responded to the announcement that BMGF provided the matched funding. Columns 4 and 5 in Table 2 report the differential treatment effect based on the source of the prospective donor. We use OLS to estimate the following specification, examining heterogeneity by donor type:

$$
\mathrm{Y}=\mathrm{a}_{0}+\mathrm{a}_{1} \mathrm{~T}_{1}+\mathrm{a}_{2} \mathrm{P} * \mathrm{~T}_{1}+\mathrm{a}_{3} \mathrm{P}+\mathrm{e}
$$

where $T_{1}$ is a dichotomous variable indicating whether or not an individual was exposed to the quality signal and $\mathrm{P}$ is a binary variable indicating whether the individual previously gave to one of the "poverty-oriented" charities.

Empirical results in Table 2 consistently show that the differential treatment effect is large and statistically significant, and this differential effect exists during the matching grant period as well as afterwards. For example, for the binary outcome of whether the solicitee donates 
any amount, previous donors to poverty-related organizations are 0.41 percentage points ( $\mathrm{p}$ value $=0.024)$ more responsive to the naming of the BMGF than non-poverty donors. This result is consistent with the hypothesis that the BMGF name acts as a quality signal for those donors who understand the size and importance of the BMGF in the field of international development. Importantly, we find no BMGF-naming effect for donors whose names we received from non-poverty related charities. Although one should be cautious when interpreting these data because previous donation patterns are not randomized across solicitees, the results are consistent with the notion that there is a large effect for donors who understand that BMGF is a major player in this area.

\section{Conclusion}

We report results from two natural field experiments which explore techniques to enhance flows of resources to charities supporting poverty reduction in developing countries. Much controversy remains about aid effectiveness, and such debates may cause doubt, and thus inaction, for potential donors. Quality signals may alleviate some of these concerns, thus raising more money for developing countries causes. Our results are thus important for donor policies regarding the funding of poverty reduction programs in developing countries.

We find that lead donors can considerably help lesser-known charities achieve their fundraising goals simply by announcing their gifts and by matching other people's gifts with their own money. Indeed, through this signaling of charity quality, large donors such as the BMGF can multiply their own gifts several times over-both during the matching period and well beyond - and attract new donors to their cause. For practitioners, this result is important in that securing a donor pyramid is one of the most important problems facing any charity. The fact that quality signaling can work to enhance both the size of gifts and the number of donors should be of great interest to this community.

More broadly, this study begins to uncover why leadership gifts are effective in motivating other people to donate money to causes supported by leaders. Economists have only recently begun to explore insights pertaining to why people give, why they remain committed to causes, and what induces them to donate additional amounts. This study advances our understanding of these topics by going beyond the short-run substitution effects observed in most previous fund-raising field experiments to generate evidence on the temporal profile of gifts across different charities over time. In doing so, the theory can be more cleanly tested, and alternative hypotheses more neatly organized. Further work is needed, however, to understand how different factors, such as the activity of the charity, the identity of the leader (in terms of its quality and connection to solicitees), and the presentation of the leader should be incorporated, or not, into models of giving in order to make them more robust. Furthermore, although the literature has clearly learned a great deal from static exercises, the true potential of field experimentation will not be reaped until we provide a deeper understanding of the dynamic issues that many of our theoretical models are built to describe. 


\section{References}

Andreoni, James (2006). "Leadership Giving in Charitable Fundraising." Journal of Public Economic Theory, 8(1): 1-22.

Andreoni, James. 1989. "Giving with Impure Altruism: Applications to Charity and Ricardian Equivalence." Journal of Political Economy, 97(6): 1447-58.

Andreoni, James. 1990. "Impure Altruism and Donations to Public Goods: A Theory of Warm-Glow Giving?” Economic Journal, 100(401): 464-77.

Auten, Gerald E., Seig, Holger, Clotfelter, Charles T. (2002). "Charitable giving, income, and taxes: an analysis of panel data." American Economic Review, 92(1): 371-382.

Clotfelter, Charles T. (1985). "The effect of tax simplification on educational and charitable organizations.” Conference Series; [Proceedings], Federal Reserve Bank of Boston, pp. 187-221

DellaVigna, Stefano, John A. List, and Ulrike Malmendier. (2011). "Testing for Altruism and Social Pressure in Charitable Giving." Quarterly Journal of Economics, Forthcoming.

Easterly, William. (2006). The White Man's Burden: Why the West's Efforts to Aid the Rest Have Done So Much Ill and So Little Good. Penguin: New York, New York.

Eckel, Catherine and Grossman, Philip J., 2003. "Rebate versus matching: does how we subsidize charitable contributions matter?" Journal of Public Economics, 87(3-4): 681701.

Feldstein, Martin S. (1975). "The Income Tax and Charitable Contributions: Part II-The Impact on Religious, Educational, and Other Organizations." National Tax Journal, 28(2): 209-2

Hermalin, Benjamin E. (1998). "Toward an Economic Theory of Leadership: Leading by Example." American Economic Review, 88(5): 1188-1206.

Karlan, Dean and List, John (2007). "Does Price Matter in Charitable Giving? Evidence from a Large-Scale Natural Field Experiment." American Economic Review, Vol. 97(5): 1174-1193.

Karlan, Dean, John A. List and Eldar Shafir (2011), "Small Matches and Charitable Giving:Evidence from a Natural Field Experiment" Journal of Public Economics.

Karlan, Dean and Margaret A. McConnell. (2012). "Hey Look at Me: The Effect of Giving Circles on Giving." NBER Working Paper No. 17737.

Landry, Craig E., Andreas Lange, John A. List, Michael K. Price, and Nicholas G. Rupp. (2006). "Toward an Understanding of the Economics of Charity: Evidence from a Field Experiment." Quarterly Journal of Economics, 121(2): 747-82.

Landry, Craig E., Andreas Lange, John A. List, Michael K. Price, and Nicholas G. Rupp. (2010). "Is a Donor in Hand Better than Two in the Bush? Evidence from a Natural Field Experiment." American Economic Review, 100(3): 958-83.

List, John A. (2011). "The Market for Charitable Giving." Journal of Economic Perspectives, 25(2): 157-180

List, John, and David Lucking-Reiley. (2002). “The Effects of Seed Money and Refunds on Charitable Giving: Experimental Evidence from a University Capital Campaign.” Journal of Political Economy, 110(1): 215-33. 
Meier, Stephan. (2007). "Do Subsidies Increase Charitable Giving in the Long Run?

Matching Donations in a Field Experiment." Journal of the European Economic Association, 5(6): 1203-1222.

Peloza, John and Piers Steel. (2005). "The Price Elasticities of Charitable Contributions: A Meta-Analysis." Journal of Public Policy \& Marketing, 24(2): 260-272.

Randolph, William C. 1995. "Dynamic Income, Progressive Taxes, and the Timing of Charitable Contributions." Journal of Political Economy, 103(4): 709-38.

Vesterlund, Lise. 2003. "The Informational Value of Sequential Fundraising." Journal of Public Economics, 87(3-4): 627-57. 
Table 1: Experiment \#1: Matching Grant versus No Matching Grant Means (Standard deviations)

Sample Frame: Prior Donors to Organization

\author{
Treatment \\ \$3:\$1 Match \\ from BMGF Offered
}

(1)

Panel A: Before Matching Grant Deadline

Response Rate

\$ Given, Unconditional on Giving

\$ Given, Conditional on Giving

Number of solicitations

Number of donations

0.009

(0.094)

0.276

(3.779)

30.751

(25.680)

25993

233
Panel B: Post-Matching Grant Deadline

Gave in Post-Match Period

0.005

$(0.068)$

\$ Given, Unconditional on Giving

0.222

(19.054)

\$ Given, Conditional on Giving

Number of solicitations

Number of donations
113.020

(418.548)

25993

51
Control

No Match Offered

(2)
0.005
$(0.070)$
0.152
(3.322)
30.484
(35.942)
25995
130

Panel C: Combined, Pre and Post Matching Grant Deadline

Total \# of Gifts

0.017

$(0.230)$

\$ Given, Unconditional on Giving

0.640

(20.796)

\$ Given, Conditional on Giving

71.354

(208.290)

25993

$0.000 * * *$

(0.048)

0.072

0.208

(2.310)

48.180

0.338

(35.592)

25995

39

0.010

$0.000^{* * *}$

(0.168)

0.288

(6.332)

57.648

(68.892)

$P$-value from

T-test

Col $1<>\mathrm{Col} 2$

$0.000^{* * *}$

$0.000^{* * *}$

0.935

25995

$\overline{* * *}, * *$, and $*$ indicate statistical signifance at $99 \%, 95 \%$, and $90 \%$, respectively. 
Table 2: Experiment \#2, Matching Grant From Bill and Melinda Gates Foundation versus from Anonymous Donor Mean (Standard Deviation) and OLS

Sample Frame: Non-Prior Donors to Organization

Mean Comparisons of Treatment and Control Mean (Standard Deviation)

$\begin{array}{ccc}\text { Treatment: } & \text { Control: } & \text { P-value from } \\ \text { BMGF Named } & \text { Anonymous } & \text { T-test } \\ & & \text { Col } 1<>\text { Col } 2\end{array}$

\section{(1)}

Panel A: Before Matching Grant Deadline

Response Rate

\$ Given, Unconditional on Giving

\$ Given, Conditional on Giving

Number of households

Number of donations

Panel B: Post-Matching Grant Deadline

Number of gifts

Amount Given, Unconditional on Giving

Amount Given, Conditional on Giving

Number of households

Number of donations
(2)

$\begin{array}{cc}0.011 & 0.009 \\ (0.104) & (0.093) \\ 0.413 & 0.291 \\ (5.569) & (4.365) \\ 37.589 & 33.688 \\ (37.783) & (32.886) \\ 30740 & 30743 \\ 338 & 266\end{array}$

\subsection{6}

(0.077)

0.188

(5.532)

65.557

(80.271)

30740

88

(95.388)

30743

61
(3)

$0.003 * * *$
$0.002 * * *$
0.183

$0.000 * * *$

0.100*

0.675
OLS Results Testing for Heterogeneous Treatment Effects Coefficient (standard error)

$\begin{array}{cc}\text { BMGF } & \text { Additive Effect for } \\ \text { Treatment Effect } & \begin{array}{c}\text { Prospects from Poverty- } \\ \text { Related Charities }\end{array}\end{array}$

(4)

(5)

$0.004^{* *}$

0.001

(0.000)

0.070

(0.048)

2.670

(3.640)

(0.002)

$0.198 * *$

(0.089)

5.103

(5.495)

61483

604

$\begin{array}{ccc}0.001^{*} & & 0.0031^{* *} \\ (0.000) & & (0.001) \\ 0.018 & & 0.1995^{*} \\ (0.045) & & (0.110) \\ -8.960 & & 52.1004^{*} \\ (17.358) & & (30.113) \\ & 61483 & \\ & 149 & \end{array}$

Panel C: Combined, Pre and Post Matching Grant Deadline

Number of gifts

0.021

$(0.234)$

0.017

$0.053^{*}$

0.000

$0.0123 * * *$

(0.241)

0.572

(11.967)

(11.074)

73.465

66.095

Amount Given, Conditional on Giving

(87.803)

(99.388)

30743
0.070

(0.106)

$-1.594$

(9.351)
(0.002)
(0.004)

$0.6331^{* * *}$

(0.217)

$31.8017^{* *}$

(14.977)
Number of households

30740

0.335

1483

Orthogonality test for source of name, from regression of assignment to treatment on indicator variable for source of donor: F-test = 0.11,

p-value $=0.9998 . * * * * *$, and $*$ indicate statistical signifance at $99 \%, 95 \%$, and $90 \%$, respectively. 